\title{
Das palavras e das coisas curiosas: correspondência e escrita na coleção de notícias de Manuel Severim de Faria
}

\author{
Ana Paula Torres Megiani
}

Notícias impressas ou manuscritas: a visibilidade do mundo

La velocidad de las noticias y el ir y venir de las cartas no és más que un capitulo de la lucha contra el espacio. Fernand Braudel, El Mediterráneo y el Mundo Mediterráneo en la Época de Filipe II

Em uma passagem pouco revisitada, J. Capistrano de Abreu assim se refere aos primeiros passos de aprendizado da leitura do colono português no Brasil seiscentista Vicente Rodriguez Palha:

Os engenhos ricos tinham um capelão com quem os meninos do senhor e outros a quem o permitia começavam os rudimentos de leitura, ordinariamente em cartas de mão, que os livros não eram comuns: na falta das obras de João de Barros, leia-se o que a tal respeito escreve Manuel Severim de Faria na vida do autor das Décadas. Talvez assim se iniciasse nas letras o futuro historiador.

Desse modo começou a ler e escrever o menino que se tornaria Frei Vicente do Salvador, aquele que foi considerado o primeiro autor da história do Brasil, provavelmente instruído por um capelão de engenho como aprendiz de primeiras letras em cartas de mão.

As breves suposições de Capistrano de Abreu acerca da instrução infantil de Frei Vicente não nos parecem, todavia, irrelevantes, já que foi este franciscano, nascido de uma família de pequenos senhores de terra na região de Salvador da Bahia, o encarregado de realizar a importante encomenda do Chantre da Sé de Évora, Manuel Severim de Faria. A obra, con- 
cluída em 1627, é hoje considerada fundamental para o conhecimento da primeira época da conquista e formação da América portuguesa, tendo permanecido manuscrita até meados do século XIX, quando, segundo o próprio Capistrano de Abreu, João Francisco Lisboa a teria encontrado e copiado diretamente do códice existente na Torre do Tombo. ${ }^{1}$

O caso da encomenda, composição e suposto esquecimento do manuscrito de Frei Vicente do Salvador, alfabetizado nos primórdios do século XVII em pleno interior da Bahia, como dissemos, é um dos inúmeros que envolveram a figura de Manuel Severim de Faria (1583-1655), cujo ambiente letrado formado por uma vasta rede de informantes em várias partes do reino de Portugal e do Império tornou-se nosso objeto de estudo nos últimos anos. ${ }^{2}$ Trata-se de uma malha de correspondências oriundas de várias partes dos reinos de Portugal e Espanha, da Europa, Índia, África e América, centralizada na cidade de Évora, desde a última década do século XVI até meados do XVII. Inaugurada pelo Chantre e continuada por seu sobrinho Balthazar de Faria Severim, a rede de informações resultou na criação de um considerável volume de documentos manuscritos, hoje dispersos e em parte desaparecidos, que se destinavam à composição de obras de história raramente concluídas, elaboradas predominantemente nas formas de Anais e Décadas, e remetidas aos correspondentes. ${ }^{3}$

O caráter extraordinário dos códices de Severim de Faria é determinado pelo fato de vários autores do século XVII terem colaborado nas relações de notícias; em contrapartida, receberam contribuições da livraria de Évora para a composição de suas obras. Além de Luís Mendes de Vasconcelos, Diogo do Couto e Frei Vicente do Salvador, ${ }^{4}$ são mencionadas pelos pesquisadores conexões com Jorge Cardoso, autor do Agiológio Lusitano, e João Franco Barreto, que escreveu a importantíssima relação de obras e livrarias existentes em Portugal na primeira metade do seiscentos denominada Biblioteca Lusitana. ${ }^{5}$ Duarte Nunes de Leão também está entre os referidos que partilharam esse ambiente letrado, embora não haja comprovação de que de fato tenha com ele trocado correspondência. Frei Cristóvão de Lisboa, irmão mais novo de Severim de Faria, que vivera entre os nativos do Maranhão na segunda década do século XVII, e Ambrósio Fernandes Brandão são os outros correspondentes na América portuguesa, embora no tocante ao segundo seja apenas constatada na $\mathrm{Li}$ - 
vraria do Chantre a existência do manuscrito de Diálogos das Grandezas do Brasil, que também permaneceria manuscrito até o século XIX. ${ }^{6}$

Contudo, os materiais reunidos e catalogados na Livraria do Chantre não se restringiam a documentos escritos, impressos e manuscritos, estes organizados em cerca de 400 volumes de maneira sistemática e muitas vezes com o inovador método classificatório alfabético; ${ }^{7}$ era também um colecionador de raridades 'antigas', medalhas, gravuras, peças, armas, conchas, pedras de bezoar, animais vivos e empalhados, couro e pele de bichos, que constituíram um verdadeiro Gabinete de Curiosidades no centro do Alentejo durante a primeira metade do século XVII. ${ }^{8}$

Nosso interesse pelos conjuntos de manuscritos reunidos em Évora, bem como as questôes emanadas das pesquisas com a livraria e a rede de correspondentes do Chantre, seu amplo espectro de influências e ainda a grande germinação de escritos que deles surgiram ao longo dos séculos seguintes, foram os pontos de partida para esta pesquisa que tem nos levado aos vários conjuntos de fontes, hoje dispersas, que a ele pertenceram. Segundo Ramada Curto, a cultura letrada da primeira metade do século XVII pode ser caracterizada pela difusão da moda das livrarias pessoais, fato que envolve principalmente a questão da catalogação e organização de volumes impressos, mas especialmente os manuscritos. ${ }^{9}$

Já para Fernando Bouza-Álvares, que ultrapassou consideravelmente as reflexóes desenvolvidas por Roger Chartier, Robert Darnton e Peter Burke $^{10}$ acerca da história do livro e da leitura, embora na Península Ibérica as práticas relacionadas aos impressos apresentassem inúmeros limites em função da existência de diversos níveis de censura e coerção, é possível mapear uma ampla rede de circulação de textos manuscritos, sobretudo copiados. ${ }^{11}$ Em dezenas de artigos dedicados ao estudo da história cultural do reinado de Filipe II e do Século de Ouro, mas sobretudo em seu livro Corre manuscrito, Bouza procura destrinçar redes de informações e cadeias de reprodução de cópias que escaparam ao controle dos inquisidores ibéricos, difundindo idéias e notícias, enveredando pelo mundo da preservação e do apagamento da memória. ${ }^{12}$

Segundo sua perspectiva, para além da estratégia de sobrevivência ao controle, a prática de compor manuscritos pessoais, burocráticos, reais etc. apresenta uma série de especificidades em relação ao livro impresso, 
guardando profundo vínculo com os níveis oral e visual. Se para grande parte da historiografia produzida no século XX a Idade Média continuou associada ao predomínio das comunicações icônico-visuais e a Época Moderna foi considerada, por excelência, o tempo do nascimento da comunicação impressa, a partir da escrita racional, política e científica; paradoxalmente, Bouza nos mostra em seus trabalhos que o oral e o visual estão presentes de modo intenso na escrita dos séculos XVI e XVII, seja ela impressa ou manuscrita, tendo em vista, sobretudo, a intensidade de mecanismos de memória vinculados à retórica e à representação visual. ${ }^{13}$

Desse modo, "não é possível defender, por exemplo, que as imagens serviam de instrumento do tradicional e do ortodoxo, e que, ao invés, a escrita fosse a aliada do revolucionário e do inovador”. Tal visão, simplista para ele, deve-se a um enfoque equivocado segundo o qual o cristianismo de cunho reformista teria encontrado seu desenvolvimento por meio da eliminação do elemento visual com relação à fé, enfatizando a dimensão da palavra escrita e da interpretação individual das Sagradas Escrituras por meio do texto impresso; enquanto o cristianismo católico teria se conservado, sobretudo na zona mediterrânea, por meio da censura inquisitorial aos livros e pelo uso das imagens como recurso de conversão e fortalecimento da fé entre os adeptos.

A abordagem que reforça a idéia de uma dicotomia cultural entre sul e norte da Europa, com claros desdobramentos para as regiōes respectivamente conquistadas e colonizadas pelas monarquias ibéricas, ainda está presente em obras recentes de ampla circulação entre nós. Ao limitar o processo de construção do conhecimento no mundo ocidental ao advento e desenvolvimento do livro impresso, P. Burke, por exemplo, em livro traduzido no Brasil, congela a relação centro-periferia ao longo de toda a Época Moderna, pois entende que o domínio da tecnologia e da imprensa possuíram relação direta com o fortalecimento dos centros de poder. ${ }^{14}$ Burke traça um percurso teleológico para a história do conhecimento nos séculos XV, XVI, XVII e XVIII, deixando do lado de fora do quadro de análise muitos dos ambientes por onde circulavam os textos manuscritos, copiados no centro e reproduzidos por letrados nas periferias. Ora, tratase de um tempo em que as práticas de escrita, impressão e leitura encontram-se consideravelmente dissociadas, exigindo para tal reflexão históri- 
ca outras categorias de análise das relações de poder com a reprodução do conhecimento.

Um antídoto para a perspectiva ilusória apresentada por Peter Burke pode ser encontrado no referido trabalho de Diogo Ramada Curto, elaborado a partir dos estudos de Charles Boxer acerca do orientalismo dos escritores portugueses que viveram experiências na China e na Índia. ${ }^{15}$ Como afirma o historiador, se muito distantes entre si estão os próprios portugueses dos séculos XVI e XVIII, que diríamos de letrados e escritores de outras regiōes da Europa, afastados também pelas penas e prensas? Desse modo, acreditamos que seja essencial proceder de forma mais sistemática ao mapeamento das redes de reprodução de manuscritos no império luso-espanhol, seja a partir de impressos clandestinamente transportados, seja de outros manuscritos. Na perspectiva indicada pelos estudos de F. Bouza com conjuntos de epístolas e coleções de cópias manuscritas da monarquia espanhola, será possível ampliar as dimensões conhecidas do raio de penetração de idéias políticas e teológicas acerca da natureza, da humanidade e da cultura, bem como relatos de notícias de acontecimentos oriundos das conquistas, tal como parece ser possível constatar em circuitos como o do Chantre de Évora.

Um exemplo de estudo desse teor é o que pode ser realizado a partir de um documento manuscrito espanhol, recentemente publicado no Brasil por Stuart B. Schwartz e Alcir Pécora. Trata-se do Panegírico fúnebre ao governador do Brasil d. Afonso Furtado, de Juan Lopes Sierra (Bahia, 1676). ${ }^{16} \mathrm{O}$ autor Lopes Sierra "é uma figura misteriosa sobre a qual nada se sabe, com exceção das informações que ele fornece a seu respeito nessa obra. Partindo do dado de que possuía 72 anos quando completou o trabalho (1676), pode-se estimar que seu nascimento teria ocorrido por volta de 1604". Desconhece-se, todavia, o local, mas ele menciona no texto ter se relacionado com muitas figuras ilustres na Bahia da segunda metade do século XVII, tais como o padre Simão de Vasconcelos, d. Rodrigo de Castelo Branco, Francisco Manuel de Melo e Bernardo Vieira Ravasco - secretário-geral do Estado do Brasil e irmão do padre Antonio Vieira. Apesar de tais relaçóes, nenhuma menção foi localizada nos arquivos portugueses a respeito de seus vínculos com a Coroa ou a administração lusa na América. Segundo Schwartz, "não é de todo impossível que Lopes 
Sierra fosse um embusteiro, um impostor das letras, que, por meio de supostas conexões, falsas referências e autopromoção, esperava cair nas boas graças de algum benfeitor rico ou poderoso". Por essa razão denomina-o sicofanta literário, um velhaco que procurava promover-se por meio de suas qualidades como autor de encômios. Ou ainda, "deve-se considerar a possibilidade de J. Lopes Sierra ser um pseudônimo. Gregório de Matos, Manuel Botelho de Oliveira e muitos dos literatos baianos do período, se não todos, eram capazes de escrever em espanhol". Hipótese descartada em seguida devido ao fato de haver muitos erros de escrita de topônimos do Brasil ou de ortografia do português, o que indica ser o autor realmente de língua espanhola. ${ }^{17} \mathrm{O}$ Panegírico de J. Lopes Sierra é um manuscrito que nos confirma a já referida vinculação entre os espaços de dominação luso-espanhola, e um estudo mais acurado do documento poderia revelar também novos dados acerca da escrita e da leitura no século XVII, nas partes coloniais.

Mas voltemos às conexões do Chantre.

\section{O tema dos holandeses da Bahia na correspondência do Chantre}

Uma das maneiras de recompor o processo de elaboração das memórias anuais escritas por Manuel Severim de Faria consiste em localizar os escritos de seus informantes e conjuntos de notícias enviadas por eles a Évora. Tais conjuntos são atualmente raros, mas é possível ler uma pequena parte dessa correspondência na Biblioteca Nacional do Rio de Janeiro, num códice pertencente à Coleção Moreira da Fonseca e recolhido por tratar especialmente da questão da invasão da Bahia pelas tropas holandesas em 1624-25. ${ }^{18}$ Enviadas de Lisboa por Luis Leitão Tavares, de Laneiros por frei Bernardo de Gost, e de Luanda pelo padre Matheus Cardoso a Évora, as cartas não estão todas diretamente remetidas ao Chantre, mas têm inúmeras referências a ele, o que significa que deveriam ser lidas primeiramente por um secretário, provavelmente seu sobrinho Balthazar. Tratam de assuntos vários, com grande relevância para o envio de impressos - livros, gravuras e retratos - de conteúdos de interesse, como textos clássicos traduzidos, imagens de representações de cidades e figuras ilustres da época ou do passado europeu, narrativas de episódios de 
naufrágios, cerimônias de corte e, sobretudo, a guerra contra os holandeses na Bahia. ${ }^{19}$

Entre os meses de julho de 1625 e março de 1626 foi praticamente ininterrupta a comunicação entre eles, destacando-se cada vez que chegavam novas notícias do Brasil a respeito da guerra, bem como dos sucessos da expulsão, das relações de acontecimentos censuradas e depois publicadas. Vale ressaltar que as cartas do padre Matheus Cardoso remetiam, de Angola a Évora, muitas notícias sobre o Brasil, aproveitando-se do fato de inúmeras embarcações partirem de Luanda para a Bahia e Pernambuco levando, além de peças para escravidão, notícias que em seguida seriam dirigidas para Lisboa. ${ }^{20}$

Novamente Stuart Schwartz publicou um importante artigo a respeito da mobilização de tropas luso-espanholas para defesa e reconquista de possessões na América portuguesa durante a última fase da União Ibérica. Nesse artigo, intitulado "A jornada dos vassalos: poder real, deveres nobres e capital mercantil antes da Restauração, 1624-1640”, o autor apresenta a relação completa de textos impressos sobre o episódio de expulsão dos holandeses da Bahia, em castelhano e português, escritos em diversos gêneros, entre eles uma peça de Lope de Vega. ${ }^{21}$ Além dos impressos, menciona a existência de manuscritos localizados em arquivos espanhóis e mesmo napolitanos, compostos por soldados que participaram nas tropas de combate. ${ }^{22}$

Para Schwartz, os relatos da jornada de 1625 constituem um momento de virada nas relações entre os vassalos e as coroas unidas sob os Habsburgo, e a partir da análise desses textos apresenta, "por um lado, a luta entre certos grupos sociais na sociedade ibérica e, por outro, os pontos de relação desses grupos com o Estado". ${ }^{23}$ Trata-se de um estudo de cultura política extremamente refinado, e raramente encontrado com relação à história militar seiscentista da América portuguesa.

Contudo, notamos que Schwartz não menciona a presença do tema da invasão da Bahia na correspondência do Chantre que aqui utilizamos, possivelmente porque os conteúdos tratados nas cartas relativos à expulsão holandesa não apresentam dados inéditos sobre as estratégias de formação e combate das tropas. Consideramos, todavia, que a relevância dessas notícias consiste, justamente, em demonstrar a agilidade da comuni- 
cação e as formas de circulação de relatos variados em circuitos paralelos aos centros de decisão. Em breve parágrafo acerca dessa agilidade, Sérgio Buarque de Holanda intuíra que "na Espanha e em Portugal a notícia da captura da capital da colônia brasileira teve enorme repercussão e despertou o patriotismo da nobreza, que em grande número se alistou para o combate. Uma poderosa esquadra ibérica conjunta, a maior que até então cruzara o equador, libertou a Bahia em abril de 1625". ${ }^{24} \mathrm{~A}$ idéia de patriotismo ganha no texto de Schwartz maior precisão, tida como aumento do vínculo das elites militares portuguesas aos mecanismos de controle da Coroa.

Em nossas esparsas notícias remetidas de longe é possível notar, em convergência ao artigo de Schwartz e às suposiçóes de S.B. de Holanda, que se trata, de fato, de um evento que mobilizou um grande número de pessoas - entre clérigos, leigos, nobres, militares e fidalgos - em torno de discussões comuns; mas para além desse aspecto apresentam idéias e versões não veiculadas nas relações impressas, estas muito utilizadas pela historiografia - tais como: impressóes sobre o comportamento violento dos soldados castelhanos em relação à população local e aos soldados portugueses; declarações de interesses políticos de funcionários da Coroa portuguesa em alcançar postos, honras e mercês do monarca; e ainda a censura de algumas dessas relações impressas que continham justamente tais comentários.

Vale lembrar que nosso intuito não é o de contrapor as notícias reveladas pela correspondência com os relatos oficiais publicados, mas de compreender, no âmbito do manuscrito pessoal, o feixe de problemas decorrentes do enfrentamento das tropas luso-espanholas na Bahia e a circulação das narrativas desses acontecimentos pelas várias partes que margeiam o Atlântico, agora conectadas pelo circuito mercantil. O caráter mais particular dessas epístolas permite-nos perscrutar a recepção dos acontecimentos longínquos no tempo no raro momento de impacto sobre os indivíduos que escrevem e lêem tais relatos.

As primeiras notícias dessas cartas chegam de Luanda, a 10 de dezembro de 1624, pela letra do missionário Matheus Cardoso, que conta:

Depois q cheguei a esta terra tenho escrito a VM por via da Bahia e aos 3 de julho, por Pernambuco a 13 do dito mês e aos 30 de agosto por hua caravella que daqui foi emdireitura a $\mathrm{L}^{\mathrm{xa}}$ com aviso da vinda da nossa via- 
gem a e de tudo o q tinha socedido ate os ditos 30 dias de Agosto de 624. [...] [fols. 1]

Estando as cousas nestes termos tivemos novas por via do Rio de Janeiro como a Bahya estava tomada dos holandeses, e dahi a pouco tornou a segundar a nova e foi o $2^{\circ}$ aviso que mandou o capitão mor do Rio de Janeiro ao governador de Angola, avisando e o me tinha novas q os olandezes desses q ião mandar 8 naus ao Rio de Janeiro para o tomar, e 4 a Angola, o q nos não podiamos crer, visto aver dous dias que deste porto se tinhão ido os olandeses mas dentro em poucos dias aos 30 de outubro amanhecerão avista da Loanda 8 embarcaçõos de olandeses, 3 naos muito grandes e os mais de menos porte, mas todas bem artilhadas e não deixam de causar medo a Loanda; [...] [fols.1 e 2] $]^{25}$

Embora a Bahia estivesse ocupada desde meados de maio de 1624, infelizmente as cartas anteriores mencionadas pelo autor desta não fazem parte do códice existente na Biblioteca Nacional do Rio de Janeiro. ${ }^{26}$ Contudo, é possível perceber, além do ritmo e da freqüência da correspondência, também o percurso que elas faziam de acordo com a chegada e partida dos navios. Nota-se o grande interesse em informar de maneira rápida e constante sobre os acontecimentos ligados à invasão. A propósito dos tempos de circulação da correspondência, lembramos o modo como Fernand Braudel tratou criticamente a questão dos ritmos do transporte de mercadorias no Mediterrâneo a partir da velocidade da chegada de notícias dos sucessos militares, entre outros os da tomada de La Goleta e Túnis. Nesse sentido afirma Braudel:

Seguir la pista a la difusión de las grandes noticias es también una manera de medir velocidades excepcionales. Las noticias tenen alas. [...] Em cualquier caso, toda medida debe considerarse con precaución, desde el momento que está confinada en una sola cifra. Y no nos olvidaremos de lo que realmente estamos mediendo. La velocidad de las noticias y el ir y venir de las cartas no és más que un capítulo de la lucha contra el espacio. ${ }^{27}$

Assim, podemos afirmar que a amplitude das distâncias intensifica o recurso aos mecanismos de comunicação. Ainda com relação ao aspecto temporal das viagens no Atlântico, J. Russell-Wood calcula que a viagem entre Lisboa e São Luís do Maranhão durava aproximadamente cinco semanas, ou seja, menos de 40 dias. Já a travessia de Lisboa para o Recife 
demorava 60 dias; para Recife, 70; e para o Rio de Janeiro, entre 80 e 90 dias. No caso do regresso das frotas do Brasil para Lisboa, partindo de Recife levavam cerca de 75 dias; de Salvador, 84; e do Rio, aproximadamente 97 dias. Já os navios isolados regressavam mais rapidamente, levando duas ou três semanas menos que as frotas. ${ }^{28}$

O segundo tema abordado nessas cartas refere-se à violência dos castelhanos nos episódios da guerra de expulsão. Abordado a partir de Lisboa em carta de 8 de novembro de 1625, Luis Leitão Tavares escreve:

[...] já VM sabera como os mais dos castelhanos q serão a Bahia estão excomungados. Por saquearem sem ninhum desaforo as Igrejas e Mosteiros trazendo todos os bens ornamentos como me disse hum soldado trazia hum o $\mathrm{f}^{\circ}$ do Duque de Aveiro quem na Armada de Castella, e não se espante VM q quirião beber pellos calices sagrados como Baltezar, e assim ande ver em si o castigos q elle tem porq de VM ouvira as lastimas dos pobres soldados purtuguezes tiverão grande lastima e em pago de seu serviço dão a alguns duas pagas por dispididas. [fols. 5 e 6$]^{29}$

E aos 15 do mesmo mês, em outra carta completa:

Aqui se soa q são mortos entre os inimigos e dos castelhanos dois mil homens e queira sua divina $\mathrm{Mg}^{\text {de }} \mathrm{q}$ pare aqui seu castigo porq o q elles fiserão na Bahia, distruindo-a mais q os próprios olandezes paresse quão ia vendo o Castigo em suas cazas, como Ds o deo a ElRey Bar depois q bebeo pollos calices sagrados e mais peças q seu pai oroubou de horas despojara aos isrraelitas. [fols.1] $]^{30}$

Tal espécie de referência às atitudes violentas e profanadoras dos soldados castelhanos são incomuns nos relatos dessa guerra, embora ainda não tenhamos verificado todas as narrativas impressas e manuscritas sobre o acontecimento.

Do mesmo modo encontramos em frei Vicente do Salvador o uso da forma-padrão ao tratar o problema da violação dos templos católicos durante os episódios de expulsão dos holandeses da Bahia.

Aqui confesso eu minha insuficiência pêra poder relatar os júbilos, a consolação, a alegria que todos sentíamos em ver que nos púlpitos, onde se haviam pregado heresias, se tornava a pregar a verdade de nossa santa fé católica, e nos altares, donde se haviam tirado ignominiosamente as imagens 
dos santos, as víamos já com tanta reverência restituídas, e sobretudo víamos já o nosso Deus em o santíssimo sacramento do altar, do qual estávamos havia um ano privados, servindo-nos as lágrimas de pão de dia e de noite, como a Davi quando lhe diziam os inimigos cada dia: Onde está o teu Deus? ${ }^{31}$

É improvável que essa descrição recorrente, que valoriza a recuperação dos espaços sagrados pelos católicos como meio para restituir a verdadeira fé junto à população tenha sido determinada pela mão da censura inquisitorial, já que, como dissemos anteriormente, o texto de frei Vicente manteve-se também manuscrito e não parece ter sido submetido à verificação dos censores do Santo Ofício, pelo menos nessa altura. Seria necessário verificar, contudo, se as razões que levaram o padre Leitão Tavares a ser implacável nas acusações feitas aos castelhanos estariam relacionadas à natureza do escrito - uma carta - ou se de fato teria circulado em outras obras esse tipo de versão.

Com relação à natureza da narrativa e os possíveis aspectos de sua composição passaremos a tocar no tema mais comum mencionado nessa correspondência. Trata-se do envio de relações impressas e informações da censura por parte do Santo Ofício, ou seja, o interesse e o controle da circulação da notícia. Na correspondência remetida em 2 de julho de 1625, frei Bernardo de Gost refere-se a acontecimentos de Lisboa e ao envio de uma Gazeta da Babia dada por um secretário de d. Fradique de Toledo, o comandante das tropas portuguesas. Reproduz ainda uma carta do rei chamando os portugueses a se organizarem para lutar contra a Inglaterra e a Holanda, cobrando ser obrigação deles a serviço del rey. Alguns dias depois, escreve de Lisboa:

Eu mandei em chegando á esta cidade a nova da tomada da Bahia com o sangue na guelra, e também a de Breda. Não le devem de faltar a VM relaçôes famosas, q por este respeito lhe não mando hua, que me deu o secretario de Dom Fradique e pode ser q já terá ahi o rol dos mortos e feridos, com tudo lhe mando com esta, e com o dito messante de quatro meses[...] [fols. 1 $]^{32}$

Novamente está clara a referência à preocupação com o envio de relações e menção ao fato de Severim de Faria ser um árduo colecionador dessas relações. Em 14 de julho, de volta a Laneiros, relata: 
[...] mando á VM estas relações q me deo o secretario de d. Fradique de Toledo, e a fiz copiar para emendar outras á outras partes, e he verdadeira e famosa, feita pello mesmo [?] do exercito, q por respeito de se ocupar em hum [?] governador coisas, q se lá acharão, não especifica nella a quantidade das peças, munições, dinh ${ }^{\text {ro }}$ e roupas que se [?] logo, pera q não mentisse no numero, coisa que muitos fazem e eu ajuntarei esta com a venia costumada, porq assim o vi em cartas, q de lá vierão e isto com obrigação de comunicar ao $S^{r}$ Chantre este papel, q por escusar trabalho, assim o peço." [fols. 1 ${ }^{33}$

Temos aqui o caso mais valioso de reprodução manuscrita em toda a rede de cartas localizada. Na correspondência enviada por Luís Leitão Tavares de Lisboa constam as seguintes ocorrências no tocante à impressão de relações e outros textos:

Ahi envio a VM o sermão q pregou o $P^{e}$ Frei Gaspar da Conceição da ordem dos pregadores na Sé da Bahia, na $\mathrm{p}^{\text {ra }}$ missa $\mathrm{q}$ se disse $\mathrm{q}^{\text {do }}$ se derão as $\mathrm{p}^{\text {ras }}$ graças publicas, entrada a cidade polla vitoria alcançada dos holandeses. [Carta de Lisboa de 8 de novembro de 1625]

Não quiserão no passo dar $L^{\text {ca }}$ para sahir hu livro q esta feito da tomada da Bahia e roubo dos castelhanos sem se tirar o q toca nos castelhanos, mas o Autor não quer e assim fiquara no sepulcro do esquecimento diseme que he de hu frade q veio de lá. [fols. 2] [Carta de Lisboa de 28 de novembro de 1625]

Ahi mando a VM a relação de toda a jornada da Bahia q fez o Pe Bertolomeu Guerreiro da Compa . aprovara muito custa hum tostão vendesse amebatinha. [Carta de Lisboa de 1ํㅡㄹ de janeiro de 1626]

Diserãome q o livro q fez o $\mathrm{P}^{\mathrm{e}} \mathrm{B}^{\text {eu }}$ Guerreiro da Bahia, era prohibido pello passo, eu saberei a certeza. [Carta de Lisboa de 17 de janeiro de 1626]

Não sei como VM me não diz na passada tem recebido o livro da tomada da Bahia q fez o $\mathrm{P}^{e} \mathrm{~B}^{\text {meu }}$ Guerreiro da Comp ${ }^{\text {ia }}$ [...] porq fiquei cuidadozo de VM não ter recebido. [Carta de Lisboa de 24 de janeiro de1626] ${ }^{34}$

E novamente frei Bernardo de Gost envia notícias de relações impressas e um livro defeso encontrável em seu convento:

O Pe Procurador teve de certo amigo, como por reliquia, hum livro de aquelles da Bahia, e o lemos conventualmente em tres especiam ${ }^{\text {nos }}$ [?] q está excelente e q pode ser de bem. E foy com condição q lho aviso logo de [?] não se acha por nenhum $\operatorname{dinh}^{\text {ro }} \mathrm{em} \mathrm{Li}^{\mathrm{xa}} \mathrm{q}$ está defeso, e assim não o pos- 
so mandar ao meu sobrinho q bem o sinto. [fols 2] [Carta de Laneiros de 5 de fevereiro de 1626]

Essa carta recebi ontem do secretario de Dom Fradique de Toledo, q reside em $\mathrm{L}^{\mathrm{xa}} \mathrm{m}^{\text {to }}$ meu amigo, e juntamente me mandou esses apontamentos de novas, q serviram pera [...] em tempo tão esteril. Se VM. Tiver algum recambio, me faça a $\mathrm{m}^{\mathrm{e}}$ de me favorecer com iguarias, $\mathrm{q}$ serviram para retemperar esta semana de dores" [fols. 1] [Carta de Laneiros de 9 de fevereiro de 1626]

Ocorrem ainda notícias confidenciais a respeito do governo das terras do Brasil, tal como a que foi dada por Leitão Tavares:

Afirmão q Diogo Luis de Viveira não ira já com as naos este anno ao Brasil porq não quer ir por $\mathrm{G}^{\text {or }}$ sem lhe [fols. 2] concederem o poder ir usar de seu governo dentro em Pernambuquo, a qual autoridade levarão todos os guovernadores passados tirando este q perdeo a bahia Diogo de mendonça $\mathrm{q}$ aseitou logo o cargo com essa condição. A causa principal destas questōes he Mathias de Albuquerque irmão do genro do $\mathrm{G}^{\text {or }} \mathrm{d}$. Diogo de Castro $\mathrm{q}$ esta per capitão mor em Pernambuquo assim q Dom Diogo favorece esta causa $\mathrm{m}^{\text {to }}$ per entender q no mesmo instante q o $\mathrm{G}^{\text {or }}$ daquelle estado puser o pé em Pernambuquo se não faz caso do capitão mor da terra e assim vera VM q per respeitos particulares se perde hua Provincia. [Carta de Lisboa de 26 ou 28 de março de 1626$]^{35}$

E Matheus Cardoso, opinando sobre o desempenho do governador de Angola:

[...] o senhor governador, que nestas guerras tem mostrado muito animo, esforço, prudencia, e virtude, e se continua conforme seus principios sera hum retrato de bons governadores, mas como elle tem debaixo dos pes o interece tudo fara bem, e senão levar Pa Portugal dro levara fama de Santo $\mathrm{G}^{\text {or }}$ e sua Magde lhe fara e dara as riquezas q outros daqui tem tirado encomendas pera seos filhos. [fols. 3] [Carta de Luanda de 10 de dezembro de 1624] ${ }^{36}$

As cerimônias de ação de graças à tomada da Bahia são também assunto dos correspondentes. Em 15 de novembro de 1625, Leitão Tavares acrescenta à lateral de uma de suas cartas o seguinte comentário:

[...] na Cathedral desta cidade se derão as graças polla vitoria alcançada dos Olandezes na Bahia estando fora o Santissimo Sacramento disse a missa o Deão e pregou Joane Mendes de Tavira fo do $\mathrm{C}^{\text {de }}$ de S. João da Pesqueira. ${ }^{37}$ 
Já em 14 de julho do mesmo ano frei Bernardo de Gost comentara os ânimos dos habitantes dizendo:

Aos 7 deste fuy á $\mathrm{Li}^{\mathrm{xa}}$ e me detive la toda a semana, e fuy banqueteado de $\mathrm{Hi}^{\mathrm{mo}}$ de melo e do presidente Nuno de Mendonça, q cada hum quis seu dia, foi semana de famosas novas da Bahia e de Breda festejadas com $\mathrm{m}^{\text {tas }}$ luminarias, e peças de artilheria, e com particular dos da Bahia como caseiras..$^{38}$

Em seguida, agradece ao Chantre e comunica-lhe o fato de não necessitar mais de ajuda para acolher os religiosos em caso de acontecer uma invasão de Lisboa:

Com estas tomadas de Breda e da Bahia se tem alevantado os espiritos de $\mathrm{m}^{\text {dos }}$ e he notavel o animo de $\mathrm{L}^{\mathrm{xa}}$ e assim os toscos penedos tem em si milhor graça, ainda q não sejão continua morada das Nereidas, e dos encantados espadartes, com tudo já os estão olhando de longe, e quasi quasi se achegão de modo q com estas sombras boas de alegres esperanças da paz e quietação amiga, escusaremos de a VP o trabalho, a q se offerecia, de agazalharmos a todos nesse sanctuario, mas não me escusarei eu de mandar á VP os devidos agradecim ${ }^{\text {tos }}$ por tanta merce, $q$ bem sei e tenho por $\mathrm{m}^{\text {to }}$ certo, q quando o viesse per estes baixos qualq ${ }^{\text {er }}$ alteração de guerra, nos ouvera $\mathrm{Vp}$ de receber a todos com abraços de Pay, pois com elle abraça os estranhos [...][fols. 2] $]^{39}$

Finalmente, não só de cartas de notícias dos religiosos vinham recheadas as bagagens dos navios; outros conteúdos as enriqueciam, como este enviado pelo próprio Matheus Cardoso de Angola:

[...] na caravela passada mandei a VM hum papagayo da terra dirigido ao Sr Pe d'Azevedo agora mando 4 pelos de onça duas com unhas e dentes mayores q a q VM tem na livraria pode dellas fazer presentes. [...] [fols. 3] [Carta de Luanda de 10 de dezembro de 1624] ${ }^{40}$

Apresentados brevemente os temas mais freqüentes, passamos a uma reflexão que se encontra ainda em construção acerca desse processo de remessa de notícias, relatos e seu papel na consolidação de um conhecimento/memória acerca do mundo novo na primeira metade do século XVII. 
Mais uma vez A.J.R. Russell-Wood, na mesma obra acima referida, destaca a importância do registro e da circulação de informaçōes entre as partes do Império português durante os séculos XV, XVI e XVII para a construção de um conhecimento novo e de uma memória desse conhecimento, produzido a partir do uso de relatos orais de pessoas que regressaram de temporadas no além-mar. Para ele, "a qualidade, a riqueza e a diversidade das informações reunidas estão patentes em crônicas, narrativas de viagens, relatórios de embaixadores, cartas de jesuítas, diários e correspondência oficial". ${ }^{41}$ Como elas passam da forma oral para os manuscritos particulares, as relações e, finalmente, o relato mais formal impresso, e os possíveis enviesamentos desse percurso, tem sido nossa grande preocupação.

Assim como as obras de arte e arquitetura constituem o patrimônio e a memória de culturas da edificação, as narrativas e notícias escritas que correram os mares em meio a peças escravas, ouro e especiarias durante os séculos XVI e XVII formam o edifício de papéis que não se encontra erigido a partir de corolários tratadísticos e padróes estéticos. Vale lembrar que a ampla dimensão da escrita descritiva do Império português, que se constitui como primeiro estágio de uma nova memória no conjunto de cartas enviadas a Évora, está elaborada de maneira extremamente coloquial, muito próxima à oralidade da língua falada, contendo grande riqueza de detalhes com relação ao estado das coisas entre o Brasil, Angola, Lisboa e o Alentejo. Sérgio Buarque de Holanda qualificara essa característica de arcaizante, denominando-a atenuação plausível, ou a pouca inclinação dos cronistas e viajantes portugueses de fabular sobre o Novo Mundo. A tese, que causou impacto e ainda causa, deve, contudo, ${ }^{42}$ ser reconsiderada dentro de seus limites. Algumas tentativas de abordagens acerca dessa capacidade narrativo-descritiva dos textos portugueses têm sido aventadas. Alguns denominam-na noticiosa, outros jornalística ${ }^{43}$; temos procurado entendê-la como uma memória em movimento.

\section{Notas}

${ }^{1}$ ABREU, J. Capistrano de. Notas preliminares a: SALVADOR, Frei Vicente do. História do Brasil (1500-1627). Belo Horizonte/São Paulo: Itatiaia/Edusp, 1982, p. 29 e 32.

${ }^{2}$ A pesquisa sobre $\mathrm{o}$ ambiente letrado e as conexões do evorense Manuel Severim de Faria teve início na tese de doutorado, defendida em 2001, quando tivemos a oportunida- 
de de conhecer seus manuscritos referentes, entre outros assuntos, à visita dos Filipes a Lisboa. Cf. MEGIANI, Ana Paula T. O rei ausente. Festa e cultura politica nas visitas dos Filipes a Portugal (1581 e 1619). São Paulo: Alameda/Fapesp/Cátedra Jaime Cortesão, 2004. Entre 2002-2003 demos continuidade à pesquisa em um estudo em nível de pósdoutorado, financiado pela Fapesp, intitulado A pedra e a tinta: engenheiros e impressores no Portugal filipino, na tentativa de compreender a circulação, edição e censura de livros em Portugal no período da União Ibérica.

${ }^{3}$ As obras atualmente publicadas de Manuel Severim de Faria são: Discursos vários politicos (introdução, actualização e notas de Maria Leonor Soares Albergaria Vieira). Lisboa: Imprensa Nacional/Casa da Moeda; Notícias de Portugal. Introdução, actualização e notas de Francisco A. Lourenço. Lisboa: Colibri, 2003.

${ }^{4}$ Recentemente publicamos o estudo acerca dessas conexōes em MEGIANI, Ana Paula T. Politica e Letras no tempo dos Filipes: o Império Português e as conexóes de Manuel Severim de Faria e Luis Mendes de Vasconcelos. In: BICALHO, Maria Fernanda Baptista; FERLINI, Vera Lucia Amaral. Modos de governar. Idéias e práticas políticas no Império Português. Séculos XVI a XIX. São Paulo: Alameda/Cátedra Jaime Cortesão-USP, 2005, p. 239-256.

${ }^{5}$ A respeito cf. FERNANDES, Maria de Lurdes Correia. A biblioteca de Jorge Cardoso (1669), autor do Agiológio Lusitano. Cultura, erudição e sentimento religioso no Portugal moderno. Porto: Faculdade de Letras da Universidade do Porto, 2000.

6 "Paralelamente, as actividades do Chantre de Évora afiguram-se cruciais na construção de uma rede de homens de letras e na dinamização da vida acadêmica eborense. De facto, a sua biblioteca, consultada por muitos, ocupa o centro de um circuito de comunicação e de relações epistolares à escala planetária. Severim exemplifica bem até que ponto se intensifica, ao longo da primeira metade de Seiscentos, um gosto pelo livro e pela leitura em paralelo com a emergência de uma nova configuração do campo literário." CURTO, Diogo Ramada. A história do livro em Portugal: uma agenda em aberto. In: Leituras, $\mathrm{n}^{\text {os }}$ 9-10, outono 2001-primavera 2002, p. 28.

${ }^{7}$ A melhor relação da coleção de manuscritos e impressos que pertenceram ao Chantre de que se tem notícia foi realizada pelo conde da Ericeira, quando do levantamento da Livraria dos Condes de Vimieiro, e publicada na Collecçam dos Documentos e Memorias da Academia Real da Historia Portugueza, neste anno de 1724 se compuzerão, e se imprimirão por ordem dos seus Censores, Dedicada A ElRey Nosso Senhor, seu augustissimo protector, e ordenada pelo Marquez de Alegrete Manoel Telles da Sylva, Secretário da mesma Academia. Lisboa Occidental, Officina de Pascoal da Sylva, Impressor de sua Magestade, e da Academia Real, MDCCXXIV, ao abrir a primeira relação afirma Ericeira: "A Livraria do Conde de Vimieiro será a primeira, de que dê conta; compomse de quatrocentos manuscritos, e livros raros, a amyor parte do Erudito, e Ilustre Chantre de Evora Manuel Severim de Faria, alguns de parentes seus muito scientes, outros do preclaro varão Martim Affonso de Souza." Notícias da Conferência que a Academia Real da Historia Portugueza fez em 27 de Abril de 1724, p. 4. 
${ }^{8}$ Exemplificamos o caso com o trecho da carta a seguir: "Mando a VM hum Papagayo da terra, o corpo da cor de cinza, e o rabo vermelho, he nom pode VM mandar ensinar o q quiser, e a lição q se lhe der há de ser de noite, e das escruas, e polla manhã sedo, vay encomendado ao irmão Pa Je azevedo para o mandar ao Sr Gaspar de Faria Severim.” Observação feita no verso de uma carta do padre Matheus Cardoso, enviada do Congo em 1624 - BNRio, mss 33,33,012 - códice Severim de Faria.

${ }^{9}$ CURTO, Diogo Ramada. O discurso político em Portugal (1600-1650). Lisboa: Centro de Estudos de História e Cultura Portuguesa/Projeto Universidade Aberta, 1988, p. 110-111.

${ }^{10}$ Para um balanço desses trabalhos e suas contribuições ver: CHARTIER, Roger. L'Ancien Regime Typographique: réflexions sur quelques travaux récents. Annales. ESC, 36 (1981), p. 191-209.

${ }^{11}$ Em um artigo publicado em 2001, o historiador francês Jean-Frédéric Schaub realiza um balanço da obra e das idéias de Fernando Bouza, apresentando as relações entre história cultural e história política por ele desenvolvidas. Segundo Schaub: "Les recherches de Fernando Bouza visent précisément à mettre en lumière la capacité de mobilisation massive des media à large diffusion (manuscrits, imprimés, gravures) par les autorités politiques ibériques à l'époque moderne. Cf. SCHAUB, J. F. Une histoire culturelle comme histoire politique (note critique). Annales, HSS, juillet-octobre, 2001, nos 4-5, p. 981-997.

${ }^{12}$ BOUZA , Fernando. Corre manuscrito. Una historia cultural del Siglo del Oro. Madrid: Marcial Pons, 2001.

${ }^{13}$ Em um artigo muito conhecido, Bouza apresenta a seguinte observação crítica com relação aos estudos sobre história do livro e da leitura na Época Moderna, desenvolvidos por parte dos historiadores do século XX: "Como se sabe, a historiografia contemporânea foi dominada por muito tempo - e de forma substancial - por um preconceito actualista. A aplicação deste preconceito à Idade Moderna converteu este período histórico no cenário da modernização, ou seja, no prelúdio que antecipou e comprovou o momento contemporâneo. Nesse contexto, a função do historiador não seria outra que a de explicar e de dotar de lógica as realidades contemporâneas que conhecia, desde o Estado à produção industrial. Passando pela família burguesa e pelo sentimento do eu, sem esquecer, evidentemente, a ciência e o pensamento. No campo concreto da história das formas de comunicação, tal enfoque supôs privilegiar a aparição e a consolidação das formas contemporâneas de leitura e de escrita, tendo como fundamento essa aliança [...] que associava os destinos do escrito e do racional no processo de modernização e progresso. À modernidade associar-se-ia, exclusivamente, a escrita racional, e tal explica que a partir da aparição da imprensa se viesse a condenar o oral e o icônico-visual à sobrevivência de formas certamente formosas, mas sempre retardatárias, e portadoras de valores escassamente inovadores. BOUZA, Fernando. Comunicação, conhecimento e memória na Espanha dos séculos XVI e XVII. Lisboa: Centro de História da Cultura, 2002, p. 110.

${ }^{14}$ Peter Burke, em cujo capítulo IV, denominado "O lugar do conhecimento: centros e periferias", alude: "[...] o tema principal será a crescente centralização do conhecimento, 
ligado a aperfeiçoamentos na comunicação física e também ao surgimento do livro impresso. Esses desenvolvimentos estão por sua vez ligados ao surgimento de uma economia mundial, à ascensão de algumas grandes cidades (às vezes sedes das principais bibliotecas) e acima de tudo à centralização do poder." BURKE, Peter. Uma história social do conhecimento. De Gutenberg a Diderot. Trad. Rio de Janeiro: Jorge Zahar, 2003, p. 57-58.

15 "No âmbito desta configuração, onde se fazem sentir interesses militares, comerciais e religiosos, o orientalismo - entendido como o conhecimento do Oriente e de outras civilizações pelos europeus - assume contornos específicos. E será necessário esperar pelos finais do século XVIII para assistir à formação de uma geração de 'orientalistas profissionais'. Resta saber qual a relação entre os referidos portugueses e - uma vez chegado o século XVIII, com os seus esforços iluministas de conhecimento - os denominados 'orientalistas profissionais'? À primeira vista, o que mais impressiona é a ausência de uma continuidade entre os trabalhos destes últimos e as obras dos portugueses que os precederam." CURTO, D.R. A história do livro em Portugal, op.cit., p. 20-21.

${ }^{16}$ SCHWARTZ, Stuart B.; PÉCORA, Alcir (orgs.). As excelências do governador. Trad. São Paulo: Companhia das Letras, 2002.

${ }^{17}$ Idem, Introdução de SCHWARTZ, S.B. p. 38-40.

${ }^{18}$ A coleção Moreira da Fonseca da BNRio, à qual pertence o códice Manuel Severim de Faria, contém um total de 54 códices de documentos concernentes aos domínios portugueses e ao Brasil, entre os anos de 1473 e 1920 - Discursos, memórias, ofícios, cartas, apologias e provisōes régias referentes à história e à economia do Brasil, como seus limites, rendimentos, capitanias, contratos, cobrança de impostos, e correspondências do marquês de Pombal; e a história de Portugal, como seus domínios, reis, armas e outras nações. Obras poéticas de vários autores, entre eles Gregório de Matos. Além disso, contém estudos sobre botânica, protozoários, física e química.

${ }^{19}$ É importante ressaltar que a recolha das cartas que integram o códice Severim de Faria pelo médico brasileiro Antônio Moreira da Fonseca nos arquivos portugueses foi feita segundo o critério de referência à invasão holandesa. Do conjunto de onde provêm não temos referência precisa, mas provavelmente muitas outras haveria. $\mathrm{O}$ mesmo tipo de procedimento realizou o barão de Studart quando selecionou e publicou no Brasil partes dos Anais de Severim de Faria relativas ao mesmo episódio: FARIA, Manoel Severim de. Historia portugueza e de outras províncias do occidente desde o anno de 1610 até o de 1640 da felice acclamação de el rey d. João IV. Ed. do barão de Studart, Fortaleza: Typ. Studart, 1903. Embora o título da obra tenha sido conservado como aparece nos manuscritos, o conteúdo apresenta apenas os assuntos relativos ao Brasil.

${ }^{20}$ Não pretendemos tratar aqui dos aspectos que envolveram a invasão da Bahia pelos holandeses, pois estão desenvolvidos em vasta historiografia cujo balanço pode ser visto em PUNTONI, Pedro. A mísera sorte. A escravidão africana no Brasil holandês e as guerras do tráfico no Atlântico-Sul (1621-1648). São Paulo: Hucitec, 1999. Cap. 1. Holandeses no Brasil; e, do mesmo autor As Guerras no Atlântico-Sul (A ofensiva holandesa). In: HESPANHA, António Manuel (org.). Nova história militar de Portugal. Lisboa: 2004, p. 255-267. 
21 "Publicaram-se grandes quantidades de crônicas e relatos dos acontecimentos, muitos dos quais escritos por participantes, observadores e historiadores. Ninguém que tenha prestado serviço nas tropas vitoriosas deixou, desde então, de mencionar os seus serviços para obter recompensas ou favores." Stuart SCHWARTZ. A jornada dos vassalos: poder real, deveres nobres e capital mercantil antes da Restauração, 1624-1640. In: Da América Portuguesa ao Brasil. Estudos Históricos. Trad. Lisboa: DIFEL, 2003, p. 144-45. Recentemente, um estudo publicado nesta mesma revista aborda a circulação de impressos e manuscritos sobre a guerra da Bahia. CAMENIESTZKI, Carlos Ziller; PASTORE, Gianriccardo Grassia. 1625, o Togo e a Tinta: a batalha de Salvador nos relatos de guerra. Topoi. Vol. 6, no 11, jul.-dez., 2005, p. 261-288.

${ }^{22}$ Idem, ibidem, ver nota 6.

${ }^{23}$ Idem, ibidem, p. 146.

${ }^{24}$ HOLANDA, Sérgio B. de. O domínio holandês na Bahia e no Nordeste (colaboração de Olga Pantaleão). In: (coord.). História Geral da Civilização Brasileira. 4⿳亠丷a ed. São Paulo: Difusão Européia do Livro, 1972, p. 237.

${ }^{25}$ Biblioteca Nacional do Rio de Janeiro, códice Severim de Faria, mss I, 33,33,012.

${ }^{26}$ Ainda com relação às notícias, PUNTONI, P. As Guerras no Atlântico-Sul, op. cit., usa o canal de comunicação estabelecido entre o padre Antonio Vieira e o Geral da Companhia de Jesus para reconstruir o episódio da invasão de Salvador.

${ }^{27}$ BRAUDEL, Fernand. El Mediterráneo y el Mundo Mediterráneo en la Época de Felipe II. Trad. $4^{a}$ reimpr. México: Fondo de Cultura Econômica, tomo I, p. 479.

28 "Não se verificou qualquer modificação significativa na duração das viagens, entre os séculos XVI e XVIII.” A.J.R. RUSSELL-WOOD. Um mundo em movimento. Os portugueses na África, Asia e América. (1415-1808). Trad. Lisboa: DIFEL, 1998, p. 56.

${ }^{29}$ Biblioteca Nacional do Rio de Janeiro, códice Severim de Faria, mss I,33,33,004.

${ }^{30}$ Idem, ibidem.

${ }^{31}$ SALVADOR, Frei Vicente do, op. cit., p. 405.

${ }^{32}$ Biblioteca Nacional do Rio de Janeiro, códice Severim de Faria, mss I,33,33,005.

${ }^{33}$ Idem, ibidem.

${ }^{34}$ Bernardo de Gost, doc.cit.

${ }^{35}$ Luis Leitão Tavares, doc.cit.

${ }^{36}$ Matheus Cardoso, doc.cit.

${ }^{37}$ L.L. Tavares, doc.cit.

${ }^{38}$ B. de Gost, doc.cit.

${ }^{39}$ Idem, ibidem.

${ }^{40}$ M. Cardoso, doc.cit.

41 "Parece não ter havido faceta da experiência humana que tenha escapado aos olhos de lince e aos excelentes ouvidos dos portugueses, nas suas peregrinações. [...] Tais informa- 
ções forneceram os materiais usados por cronistas oficiais e por historiadores os quais, não só tinham acesso, sem restrições, a todos os relatórios que entravam em Portugal, mas podiam recorrer a testemunho oral riquíssimo daqueles que regressavam de alémmar. Igualmente, conselheiros reais, estrategas militares, prospectores comerciais e até membros do clero recorreram a essas mesmas fontes para tomar decisóes no interesse da Coroa, do País e da Cristandade.” RUSSELL-WOOD, A.J.R. op.cit., p. 97.

${ }^{42}$ HOLANDA, Sérgio Buarque de. Visão do Paraíso. Os motivos edênicos no descobrimento e colonização do Brasil. 6⿳a ed. São Paulo: Brasiliense, 1994. Cap.VI.

${ }^{43}$ Nesse sentido, ver: ALÍAS BERGEL, Antonio J. As relaçôes de sucessos nas origens do jornalismo. Aproximação ao mercado informativo na Lisboa do século XVII. Leitura. Rev. Bibl. Nac. Lisboa, S.3, no 14-15, abril 2004-abril 2005, p. 211-238.

\section{Referências bibliográficas}

ALMEIDA, Luiz Sávio de. Umas poucas palavras. In: ; GALINDO, Marcos; ELIAS, Juliana Lopes. Índios do Nordeste: temas e problemas (II). Maceió: Edufal, 2000, p. 13-21.

ARAÚJO, Douglas. A morte do Sertão Antigo no Seridó: o desmoronamento das fazendas agropecuaristas em Caicó e Florânia (1970-90). 2003, 364 p. Tese (doutorado em História). Universidade Federal de Pernambuco. Recife.

AUGUSTO, José. Seridó. Rio de Janeiro: Borsoi, 1954.

CASCUDO, Luís da Câmara. História do Rio Grande do Norte. 2ª ed. Rio de Janeiro: Achiamé; Natal: Fundação José Augusto, 1984.

CASCUDO, Luís da Câmara. Nomes da Terra: história, geografia e toponimia do Rio Grande do Norte. Natal: Fundação José Augusto, 1968.

CASTRO, Iná Elias de; GOMES, Paulo César da Costa; CORRÊA, Roberto Lobato (orgs.). Geografia: conceitos e temas. Rio de Janeiro: Bertrand Brasil, 1995.

CERTEAU, Michel de. A invenção do cotidiano 1: artes de fazer. 4⿳a ed. Petrópolis: Vozes, 1994.

DANTAS, José Adelino. Homens e fatos do Seridó Antigo. Garanhuns: O Monitor, 1962 .

DANTAS, Manoel. Homens d'outrora. Rio de Janeiro: Irmãos Pongetti Editores, 1941 (Bibliotheca de História Norte-Rio-grandense, IV).

DELEUZE, Gilles; GUATTARI, Félix. Mil Platôs: capitalismo e esquizofrenia. São Paulo: Ed. 34, 1997.

DINIZ, Mônica. Sesmarias e posse de terras: política fundiária para assegurar a colonização brasileira. Histórica - Revista Eletrônica do Arquivo do Estado de São 
Paulo, no 2, jun. 2005. Disponível em: www.historica.arquivoestado.sp.gov.br. Acesso em: 14 de jul. 2005.

DRUMMOND, José Augusto. A história ambiental: temas, fontes e linhas de pesquisa. Estudos Históricos. Rio de Janeiro, v. 4, n. 8, 1991, p. 177-97.

DUQUE, Guimarães. O Nordeste e as lavouras xerófilas. 2a ed. Mossoró: Esam/ Fundação Guimarães Duque; Brasília: CNPq, 1980 (Mossoroense, série C, v. CXLIII).

FARIA, Oswaldo Lamartine de; AZEVEDO, Guilherme de. Vocabulário do criatório norte-rio-grandense. $2^{\underline{a}} \mathrm{ed}$. Natal: Fundação José Augusto, 1997.

FELIPE, José Lacerda Alves; CARVALHO, Edilson Alves de. Atlas escolar do Rio Grande do Norte. João Pessoa: Grafset, 1999.

FONSECA, Antonio José Victoriano Borges da. Nobiliarchia Pernambucana, v.I. $2^{\mathrm{a}}$ ed. Mossoró: Gráfica Tércio Rosado/Esam, 1992 (Mossoroense, série C, v. 819).

Fundação Vingt Rosado. Instituto Histórico e Geográfico do Rio Grande do Norte. Sesmarias do Rio Grande do Norte, v.1 (Anteriores à Guerra Holandesa - 1716). Mossoró: Fundação Vingt-Un Rosado/Gráfica Tércio Rosado (Esam), 2000 (Mossoroense, série C, v.1.136).

GREENBLATT, Stephen. Possessões maravilhosas. São Paulo: Edusp. 1996.

GRUZINSKI, Serge. O pensamento mestiço. São Paulo: Companhia das Letras, 2001. GUERRA, Phelipe; GUERRA, Theophilo. Seccas contra a secca. 4⿳亠 ed. Mossoró: FRV/Fundação Guimarães Duque, 2001 (Col. Mossoroense, série C, v.1.203). LAMARTINE, Juvenal. Velhos costumes do meu Sertão. Natal: Fundação José Augusto, 1965.

LAMARTINE, Oswaldo. Sertôes do Seridó. Brasília: Centro Gráfico do Senado Federal, 1980.

LIMA, Ruy Cirne. Pequena história territorial do Brasil: Sesmarias e terras devolutas. São Paulo: Ediçōes Arquivo do Estado/Governo do Estado/Secretaria de Estado da Cultura, 1991.

LIRA, Augusto Tavares de. História do Rio Grande do Norte. $2^{a}$ ed. Natal: Fundação José Augusto; Brasília: Centro Gráfico do Senado Federal, 1982.

LOPES, Fátima Martins. Índios, colonos e missionários na colonização da Capitania do Rio Grande do Norte. Mossoró: Fundação Vingt-Un Rosado; Natal: Instituto Histórico e Geográfico do Rio Grande do Norte, 2003 (Col. Mossoroense, série C, v.1.379).

MACEDO, Helder Alexandre Medeiros de. Desvendando o passado índio do sertão: memórias de mulheres do Seridó sobre as caboclas-brabas. Vivência. Natal, no 28, 2005, p.145-57. 
MACEDO, Helder Alexandre Medeiros de. Os documentos do Cartório de Pombal-PB e sua importância para o entendimento da História Colonial do Sertão do Rio Grande do Norte. Mneme - Revista de Humanidades. Caicó, v. 5, no12, out./nov. 2004. Disponível em http://www.seol.com.br/mneme. Acesso em: 12 de mar. 2005.

Quando o Sertão se descobre: os documentos pombalenses e a redescoberta da História do Seridó Colonial. O Galo - Jornal Cultural. Natal: Fundação José Augusto, ano XI, no 4, abril/maio de 2000, p. 19-22.

MACÊDO, Muirakytan Kennedy de. A penúltima versão do Seridó: uma história do regionalismo seridoense. Natal: Sebo Vermelho, 2005.

MARIZ, Marlene da Silva (org.). Repertório de documentos para a História Indígena existentes no Instituto Histórico e Geográfico do Rio Grande do Norte. Mossoró: FVR/ETFRN/Uned; Natal: Secretaria de Educação, Cultura e Desportos do Rio Grande do Norte, 1995.

MEDEIROS FILHO, Olavo de. Cronologia Seridoense. Mossoró: Fundação Guimarães Duque/Fundação Vingt-Un Rosado, 2002 (Col. Mossoroense, série $\mathrm{C}$, v. 1.268).

deral, 1984.

. Indios do Açu e Seridó. Brasília: Centro Gráfico do Senado Fe. Notas para a História do Rio Grande do Norte. João Pessoa: Unipê, 2001. . Os holandeses na Capitania do Rio Grande. Natal: IHGRN, 1998. . Verdadeira origem da cidade de Caicó. O Poti. Natal: 1986.

MEDEIROS, Ricardo Pinto de. O descobrimento dos outros: povos indígenas do sertão nordestino no período colonial. 2000. 280p. Tese (doutorado em História do Brasil). Universidade Federal de Pernambuco. Recife.

MELO, Protásio Pinheiro de. Contribuição indígena à fala norte-rio-grandense. Natal: Imprensa Universitária, 1971. (Arquivos do Instituto de Antropologia Câmara Cascudo, Série especial - Lingüística, n.1).

MONTEIRO, Denise Mattos. Introdução à História do Rio Grande do Norte. Natal: Edufurn, 2000.

. Terra e trabalho em perspectiva histórica: um exemplo do sertão nordestino (Portalegre-RN). Caderno de História. Natal, v. 6, no1, p. 5-41, jan./dez. 1999.

MONTEIRO, Eymard L' Eraistre. Caicó: subsidios para a história completa do município. Recife: Escola Salesiana de Artes Gráficas, 1945. 
Das palaVras E DAS COISAS CURIOSAS: CORRESPONDÊNCIA E ESCRITA NA coleção de notícias de Manuel Severim de Faria • 47

PEREGALLI, Enrique. A América que os europeus encontraram. 13ำ ed. rev. atual. São Paulo: Atual, 1994.

PIRES, Maria Idalina Cruz. Guerra dos Bárbaros: resistência e conflitos no Nordeste Colonial. Recife: Secretaria de Cultura, 1990.

PIRES, Maria Idalina da Cruz. Resistência Indígena no Nordeste Colonial: a Guerra dos Bárbaros. Nordeste Indígena. Recife, Funai, no 1, p. 67-74, 1989.

POMBO, Rocha. História do Estado do Rio Grande do Norte. Portugal: Renascença Portuguesa; Rio de Janeiro: Annuario do Brasil (Almanak Laemmert), 1922.

POMPA, Cristina. Religião como tradução: missionários, Tupi e Tapuia no Brasil Colonial. Bauru, SP: Edusc, 2003.

PUNTONI, Pedro. A Guerra dos Bárbaros: povos indígenas e a colonização do Sertão Nordeste do Brasil, 1650-1720. 1998. 200p. Tese (doutorado em História Social). Universidade de São Paulo. São Paulo.

SAMPAIO, Teodoro. O Tupi na geografia nacional. Rio de Janeiro: INL, 1987.

SCHAMA, Simon. Paisagem e memória. São Paulo: Companhia das Letras, 1996.

SEIXAS, Wilson. O velho arraial de Piranhas (Pombal) no centenário de sua elevação a cidade. João Pessoa: A Imprensa, 1961.

SILVA, Francisco Carlos Teixeira da. Pecuária, agricultura de alimentos e recursos naturais no Brasil-Colônia. In: SZMRECSÁNYI, Tamás. História econômica do Periodo Colonial. São Paulo: Hucitec/Fapesp/ABPHE, 1997, p. 123-59.

SILVA, Kalina Vanderlei Paiva da. 'Nas solidōes vastas e assustadoras': os pobres do açúcar e a conquista do sertão de Pernambuco nos séculos XVII e XVIII. 2003. 361p. Tese (doutorado em História). Universidade Federal de Pernambuco. Recife.

SILVA, Lígia Maria Osório. A 'questão da terra' e a formação da sociedade nacional no Brasil. In: II Congresso Brasileiro de História Econômica / $3^{\beth}$ Conferência Internacional de História das Empresas. Anais..., v. I. São Paulo, ABPHE/ UFF, 1996. p. 35-51.

SOARES, Antonio. Dicionário Histórico e Geográfico do Rio Grande do Norte, v. I. Mossoró: s/e, 1988 (Col. Mossoroense, v. CDXVII).

TAUNAY, Afonso de E. A Guerra dos Bárbaros. 2a ed. Mossoró: FVR/ETFRN/ Uned; Natal: Secretaria de Educação, Cultura e Desportos do Estado do Rio Grande do Norte, 1995 (Col. Mossoroense, série C, v.864).

TEENSMA, B.N. O Diário de Rodolfo Baro (1647) como Monumento aos Índios Tarairiu do Rio Grande do Norte (1998). Ethnos - Revista Brasileira de Etno-história. Ano II, no 3. Disponível em http://www.galindo.demon.nl/ethnos3/ teensma.html. Acesso em: 13 de fev. 2000. 
WORSTER, Donald. Para fazer história ambiental. Estudos Históricos. Rio de Janeiro, v. 4, no 8,1991 , p. 198-215.

\section{RESUMO}

Enquanto vigorou a Uniāo das Coroas Ibéricas (1580-1640) aprofundaram-se as relaçôes de conhecimento acerca das conquistas luso-espanholas. Alguns circuitos e conexóes surgiram constituidos por funcionários e clérigos letrados, tanto de enviados com o objetivo de registrar e descrever as partes do Oriente e do Ocidente como dos que ao lado de suas atividades administrativas e evangelizadoras enviavam informaçôes e conhecimentos delas. Manuel Severim de Faria, Chantre da Sé de Évora, criou e centralizou um desses importantes circuitos, do qual fizeram parte, entre outros, o vice-rei Diogo do Couto e os freis Cristóvão de Lisboa e Vicente do Salvador. Outros, menos conhecidos, relatavam em cartas as notícias com grande rapidez, como as da guerra contra os holandeses na Bahia em 1624-25.

Palavras-chave: União das Coroas Ibéricas, clérigos letrados, Manuel Severim de Faria.

\section{ABSTRACT}

The Iberian Crowns' Union (1580-1640) enabled a deeper knowledge of both Portuguese and Spanish conquests. Some circuits and connections arouse from the activities of enlightened bureaucrats and clergyman, commissioned to register and describe Eastern and Western parts of the world, or sent to accomplish day to day administration or evangelic duties that should be informed to their superiors. Manuel Severim de Faria, Chanter of Evora, not only created but was also at the centre of one of these important circuits, from which took also part, among others, Vice-Roy Diogo do Couto and friars Cristovão de Lisboa and Vicente do Salvador. Others, less notorious, used to send letters that traveled amazingly fast, informing such events as the War against the Dutch in Bahia, in 1624-25.

Keywords: Iberian Crown' Union, clergyman enlightened, Manuel Severim de Faria.

Recebido em novembro de 2006 e aprovado em janeiro de 2007 